\title{
Influence of keratinized mucosa on the surgical therapeutical outcomes of peri-implantitis
}

\author{
Andrea Ravidà $^{1}$ (D) | Islam Saleh ${ }^{1}$ | Rafael Siqueira ${ }^{1}$ (I) | Carlos Garaicoa-Pazmiño \\ Muhammad H. A. Saleh ${ }^{1,3}$ | Alberto Monje ${ }^{4}$ | $\mid$ Hom-Lay Wang ${ }^{1}$ (D)
}

${ }^{1}$ Department of Periodontics and Oral Medicine, University of Michigan School of Dentistry, Ann Arbor, MI, USA

${ }^{2}$ Department of Periodontology, School of Dentistry, Oregon Health \& Science University, Portland, OR, USA

${ }^{3}$ Department of Periodontics, University of Louisville School of Dentistry, Louisville, KY, USA

${ }^{4}$ Department Periodontology, Universitat Internacional de Catalunya, Barcelona, Spain

\section{Correspondence}

Hom-Lay Wang, Department of Periodontics and Oral Medicine, University of Michigan School of Dentistry, 1011 North University Avenue, Ann Arbor, MI, USA.

Email: homlay@umich.edu

Funding information

This paper was partially supported by the University of Michigan Periodontal Graduate Student Research Fund.

\begin{abstract}
Aim: To assess the impact of keratinized mucosa (KM) width around dental implants on surgical therapeutic outcomes when treating peri-implantitis.

Material and Methods: Surgically treated peri-implantitis implants were divided into two groups (KM width $<2 \mathrm{~mm}$ and $\geq 2 \mathrm{~mm}$ ). Retrospective data were obtained after implant placement (TO) and the day of peri-implantitis surgical treatment (T1). Patients were later recruited ( $\geq 1$ year after $\mathrm{T} 1$ ) for clinical and radiographic examination (T2). Outcomes were analysed using generalized estimating equation (GEE) models.

Results: A total of 40 patients (68 implants) (average follow-up: $52.4 \pm 30.5$ months) were included in this study. From T0 to T1, no differences were found between KM groups in terms of peri-implant probing depths (PPD) and bleeding on probing (BOP). However, sites with $<2 \mathrm{~mm}$ KM exhibited significantly higher suppuration (SUP) and lower marginal bone level (MBL) $(p>$.01). Between T1 and T2, no major differences were noted on PPD reduction, BOP and $\mathrm{MBL}$ changes between the two groups. GEE modelling demonstrated that MBL severity prior to surgical therapy was a better predictor for implant survival than KM width.

Conclusion: Surgical outcome in treating peri-implantitis was influenced by the severity of bone loss present at the time of treatment and not by the presence of KM at the time of treatment.
\end{abstract}

\section{KEYWORDS}

dental implants, disease management, keratinized mucosa, peri-implantitis

\section{1 | INTRODUCTION}

It is beyond dispute that dental implants have long-term ( $\geq 10$ year) survival rates over 90\% (Howe, Keys, \& Richards, 2019; Pjetursson, Thoma, Jung, Zwahlen, \& Zembic, 2012). However, dental implants are subject to biological complications known as peri-implant diseases (Renvert, Persson, Pirih, \& Camargo, 2018). While tissue inflammation is a hallmark of both peri-implant mucositis and periimplantitis, only the latter form presents with progressive loss of supporting bone (Lindhe et al., 2008). The reported prevalence of peri-implant mucositis ranged from $19 \%$ to $65 \%$ (weighted mean of $42.9 \%$ ), while for peri-implantitis prevalence ranged from $1 \%$ to $47 \%$ (weighted mean of 22\%) (Derks \& Tomasi, 2015). Peri-implantitis prevalence was positively correlated with function time and negatively correlated with threshold for bone loss (Derks \& Tomasi, 2015).

Several conditions have been identified as putative risk factors or risk indicators for peri-implantitis including diabetes, smoking, history of periodontitis, poor plaque control, lack of regular maintenance therapy, inadequate width of keratinized mucosa (KM), implant malpositioning, among others (Hammerle \& Tarnow, 2018; Schwarz, Derks, Monje, \& Wang, 2018). One factor that is routinely 
investigated is the significance of KM on peri-implant health (Chung, Oh, Shotwell, Misch, \& Wang, 2006; Kim et al., 2009; Lin, Chan, \& Wang, 2013). A lack of KM has been associated with higher levels of prostaglandin E2 (Zigdon \& Machtei, 2008), which might explain the positive effect of KM on the development and resolution of experimental mucositis in humans (Schwarz et al., 2018b). Hence, its presence seems essential for maintenance of long-term peri-implant health (Listgarten, Lang, Schroeder, \& Schroeder, 1991). While few studies reported that presence of KM was associated with peri-implantitis (Roos-Jansaker, Lindahl, Renvert, \& Renvert, 2006), there is building evidence to support a positive correlation between the presence of peri-implantitis and sites with $<2 \mathrm{~mm}$ KM (Bouri, Bissada, Al-Zahrani, Faddoul, \& Nouneh, 2008), where others suggest that the evidence to support this finding is limited (Bengazi, Wennstrom, \& Lekholm, 1996; Crespi, Cappare, \& Gherlone, 2010; Frisch, Ziebolz, Vach, \& Ratka-Kruger, 2015; Wennstrom, Bengazi, \& Lekholm, 1994; Wennstrom \& Derks, 2012). Recent data support the understanding that an adequate width of $\mathrm{KM}$ is crucial in patients exhibiting poor compliance with peri-implant maintenance (Monje \& Blasi, 2019), but plays a lesser role in fully compliant patients (Lim, Wiedemeier, Hammerle, \& Thoma, 2019).

Although disagreement exists in the literature, the majority of studies agreed that the absence or lack $(<2 \mathrm{~mm})$ of KM was more likely to be associated with increased plaque accumulation, tissue inflammation, recession, attachment loss and reduced quality of self-performed oral hygiene measures (Gobbato, Avila-Ortiz, Sohrabi, Wang, \& Karimbux, 2013; Lin et al., 2013; Ueno et al., 2016). These findings suggest that the presence of KM should be important not only for maintaining peri-implant health, but also during surgical therapy of peri-implantitis and long-term maintenance.

The influence of KM on the prevalence of peri-implant diseases can be argued according to population studies. However, it remains unknown whether the presence of KM plays a significant role in the treatment of peri-implant diseases. Hence, the aim of this study was to explore the impact of KM on the outcomes of peri-implantitis treatment before and after surgical therapy.

\section{2 | MATERIAL AND METHODS}

This retrospective study was conducted in accordance with the Declaration of Helsinki on human studies, approved by the University of Michigan School of Dentistry Institutional Review Board (IRB) for Human Studies (HUM00148346), and registered in Clinicaltrials.gov (ID: NCT03772652). Physical and digital records collected from patients treated for peri-implantitis from 2008 to 2018 at the University of Michigan School of Dentistry were screened and evaluated by three examiners (IS, AR, RS). Patients with functional treated implants were invited to participate in the study and recruited after signing a written informed consent form for data collection from January 2019 to June 2019. Strengthening the Reporting of Observational Studies in Epidemiology (STROBE) guidelines were followed during the preparation of the manuscript.

\section{Clinical Relevance}

Scientific rationale for the study: The significance of keratinized mucosa (KM) on peri-implant diseases has been extensively investigated. Nevertheless, the impact of KM on therapeutic outcomes remains unknown.

Principal findings: Keratinized mucosa might play a more crucial role in the progression of peri-implant diseases rather than in the response to surgical therapy.

Practical implication: While progression of peri-implantitis is associated with a lack of $\mathrm{KM}$, therapeutic outcomes are mainly influenced by severity of bone loss.

\section{1 | Eligibility criteria}

To be included in this study, patients had to fall under the following predetermined eligibility criteria: (a) presence of at least one dental implant previously diagnosed with peri-implantitis using the American Academy of Periodontology (AAP)/European Federation of Periodontology (EPF) 2017 World Workshop on the Classification of Periodontal and Peri-implant Diseases and Conditions guidelines (Berglundh, Armitage, et al., 2018), (b) complete clinical and radiographic pre-surgical documentation, (c) documented follow-up of $\geq 1$ year following surgical therapy for peri-implantitis with either resective or regeneration therapy (Table S1), (d) $\geq 1$ maintenance session per year within the University of Michigan School of Dentistry after surgical treatment of peri-implantitis and (e) presence of opposing occlusion. Patients were excluded if: (a) clinical and radiographic records were incomplete or not available, (b) follow-up <1 year after surgical therapy and (c) peri-implantitis treatment and maintenance therapy was rendered outside the University of Michigan School of Dentistry.

\subsection{Data collection and classification}

As part of the data collection process, all relevant patient information including gender, age at the time of the treatment of periimplantitis, self-reported cigarette consumption ( $\geq 1$ cigarette/day), diabetes and history of periodontal disease as defined by the World Workshop (Tonetti, Greenwell, \& Kornman, 2018) were collected. Patients were assessed at T0, T1 and T2, where T0 represented implant placement or prosthetic placement, T1 represented periimplantitis treatment and T2 represented follow-up after treatment where patients were recalled. Patients files were examined at TO to collect clinical parameters such as KM width and radiographs. KM width was defined as the distance measured between the free mucosal margin to the mucogingival junction at the mid-buccal site, 
utilizing the North Carolina probe (Hu-Friedy, Chicago, IL, USA). The selected cases were then separated into two groups based on the amount of $\mathrm{KM}$ : $\mathrm{KM}<2 \mathrm{~mm}$ and $\mathrm{KM} \geq 2 \mathrm{~mm}$. The following information was collected from patient files at $\mathrm{T} 1 \mathrm{~K} \mathrm{KM}$ width, radiographs, peri-implant probing depths (PPD) (recorded in millimetres using a North Carolina probe), bleeding on probing (BOP) and suppuration (SUP) (dichotomous (1/0) scale using a North Carolina probe) and peri-implant marginal bone level (MBL). Peri-implant MBL was considered as the distance between the most coronal part of the implant expected to be in bone-to-implant contact (for tissue-level implants: the interface between the polished collar and rough surface, and for bone level implants with rough surface: the platform level) to the most coronal point of the implant body in contact with bone. For each radiograph, the MBL was measured by two authors (CGP, RS) at the mesial and distal aspects of the affected implants using commercially available software (ImageJ, U. S. National Institutes of Health, Bethesda, MD, USA). MBL was also categorized in percentage (<25\%; $25 \%-50 \%$; or $>50 \%$ ) of the implant at the interproximal sites that had no bone-implant-contact considering the length of the implant. Implant design was taken in consideration for this analysis, and therefore, implants with a polished collar were analysed as complete length being from the smooth-rough interface in apical direction. Repeated measurements of 15 implants were conducted to quantify mean intra- and inter-agreement measurement errors: $0.36 \pm 0.4$ and $0.57 \pm 0.6$, respectively. Changes in the width of KM from TO to $T 1$ were observed. Implants that were initially in the $K M \geq 2 \mathrm{~mm}$ group at TO might have switched to the $\mathrm{KM}<2 \mathrm{~mm}$ group by this point (T1) or vice versa; depending on the rendered KM lose or gain.

If the treated implant was found to be in function based on the information on file in the patient chart during the last appointment in our clinic, the patient was contacted and invited to participate in this study (T2 appointment). In case of implant failure, the date of the implant removal was recorded, and the implant was included in the analysis, but the patient was not contacted (no T2 appointment). During patient recalls, all the aforementioned clinical and radiographic parameters were remeasured. In addition, plaque index (Silness \& Loe, 1964) was recorded by one expert examiner (CGP). Additional information regarding type of surgical intervention (resective surgery or guided bone regeneration), previous non-surgical therapy, number of maintenance visits, systemic antibiotic prescription, and the characteristics of the implants and prosthesis were also gathered.

\section{3 | Treatment success}

An extensive search of all available peri-implantitis treatment success criteria was performed. The most employed success criteria after treatment of peri-implantitis were defined as PPD $<5 \mathrm{~mm}$, absence of BOP/SUP, and no progressive radiographic marginal bone loss (Criteria 1) (Berglundh, Wennstrom, \& Lindhe, 2018; Cha, Lee, \& Kim, 2019; Charalampakis, Rabe, Leonhardt, \& Dahlen, 2011; Heitz-Mayfield \& Mombelli, 2014; Heitz-Mayfield et al., 2018; Isler,
Soysal, Ceyhanli, Bakirarar, \& Unsal, 2018; de Tapia et al., 2019). Criteria 1 were used to define success after both resective and regenerative treatment at T2. An additional composite modified criteria (Criteria 2) were used at T2 to define success around implant sites treated with regenerative therapy (PPD $<5 \mathrm{~mm}$, modified sulcus bleeding index [SBI] in $<25 \%$ of sites, and defect bone fill of $>25 \%$ or $>1 \mathrm{~mm}$ ) (Mombelli, Oosten, Schurch, \& Land, 1987; Renvert, Roos-Jansaker, \& Persson, 2018; Roos-Jansaker, Persson, Lindahl, \& Renvert, 2014).

\subsection{Statistical analysis}

Binary logistic regression was conducted to evaluate post-surgical outcomes based on pre-surgical KM width using generalized estimating equations (GEE) adjusted to account for differences in follow-up period, number of maintenance visits and type of procedure performed between TO, T1 and T2. The changes in BOP and SUP rates from $\mathrm{T} 1$ to $\mathrm{T} 2$ among the two KM groups were analysed with a model labelled as "interaction group KM-time." For changes in mean PPD (at six sites) and mean MBL (mesial and distal), general linear models were used under the GEE approach. The GEE methodology was used to control the intra-subject correlation due to the multiplicity of implants. The level of significance utilized in the analyses was $5 \%(\alpha=0.05)$. A logistic regression model reached a power of $82.6 \%$ to detect an odds ratio (OR) $=4$ and deemed significant in a hypothetical sample of 68 totally independent implants assuming a confidence level of $95 \%$. Due to the multi-level design of the data (several implants per patient), the power was corrected assuming a moderate intra-subject correlation $(\rho=0.5)$ resulting in a power of $72 \%$.

\section{3 | RESULTS}

One hundred forty-three patients received treatment of peri-implantitis at University of Michigan school of Dentistry; however, 103 were excluded for the following reason: 23 patients had the implants placed outside the school and information at TO were not available, 2 patients passed away, 6 patients moved and were not able to come to the appointment at T2, 14 patients could not be contacted, 33 patients had incomplete information at T0 or T1, 14 did not want to be part of the research study, 5 patients were treated before implants were restored, and for 6 patients the implants were extracted < 1 year after surgical treatment of peri-implantitis. A total of 40 patients including 22 women (55\%) and 18 men (45\%) with a mean age of $64.5 \pm 9.0$ years (range: $43-87$ years) were recruited for this study. At T0, a total of 68 implants ( $K M<2 \mathrm{~mm}=26$; $K M \geq 2=42$ ) were included in the study (Table S2). Thirteen implants with $\mathrm{KM} \geq 2 \mathrm{~mm}$ at TO (implant placement) lost $\mathrm{KM}$ width due to the peri-implant disease process and were then moved to the $\mathrm{KM}<2 \mathrm{~mm}$ group at T1 (peri-implantitis surgical treatment). Hence, 39 implants with $<2 \mathrm{~mm} \mathrm{KM}$ and 29 with $\geq 2 \mathrm{~mm} \mathrm{KM}$ were 


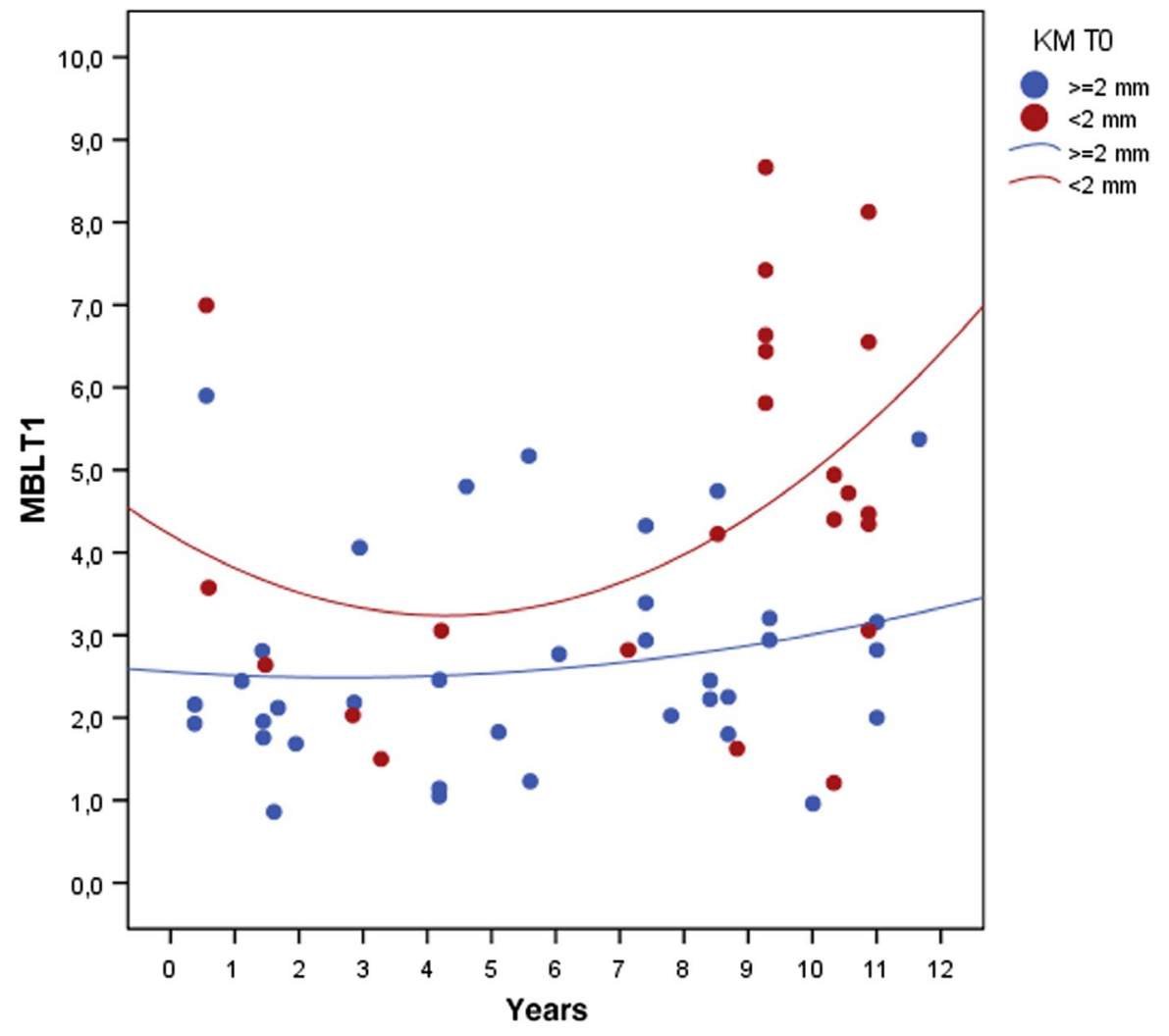

FIGURE 1 Implant marginal bone level (MBL) distribution between T0 and T1 according to time (years) and keratinized mucosa (KM) width

diagnosed with and treated for peri-implantitis (T1) receiving either resective or regenerative therapy with a mean follow-up of $52.4 \pm 30.5$ months (Figure S1). In total, $10 \%$ percent of the patients were smokers, $10 \%$ presented with hyperglycaemia, and $62.5 \%$ had a history of periodontitis at the time of the surgical phase for the management of peri-implantitis. Demographic data and relevant pre- surgical treatment of peri-implantitis (T1) information were included in Table 1.

\subsection{Changes from implant placement to the day of surgery (T0-T1)}

The duration of time between implant placement and surgical treatment of peri-implantitis was longer for dental implants with $<2 \mathrm{~mm} \mathrm{KM}$ relative to those with $\geq 2 \mathrm{~mm} \mathrm{KM}$ (T0-T1) ( $p=.087$ ). Furthermore, patients with peri-implant sites presenting with $<2 \mathrm{~mm}$ KM exhibited a similar frequency of periodontal maintenance sessions ( $p=.607$ ). The association between KM, clinical, and radiographic parameters at T1 are shown in Figure 1 and Table 2. At T1 no statistically significant difference was found between the two groups of KM width in terms of PPD and BOP $(p>.05)$. However, sites with $<2 \mathrm{~mm} \mathrm{KM}$ had a fivefold increase $(\mathrm{OR}=5.02)$ in SUP compared to sites with $\geq 2 \mathrm{~mm} \mathrm{KM}(p=.025)$. Simple linear regression using GEE to control differences in time and maintenance showed that sites with $<2 \mathrm{~mm}$ KM exhibited significantly lower MBL at T1 than sites with $\geq 2 \mathrm{~mm} \mathrm{KM}(p<.01)$. Sites with $<2 \mathrm{~mm} \mathrm{KM}$ had a fivefold higher risk for having $\mathrm{MBL}>25 \%$
( $p=.012)$ and 11-fold higher risk for MBL > 50\% ( $p=.011)$ compared to sites with $\geq 2 \mathrm{~mm} \mathrm{KM}$.

\subsection{Changes after treatment of peri-implantitis (T1-T2)}

Clinical and radiographical parameters prior surgical treatment for peri-implantitis are shown in Table 3. Twelve out of 68 implants were removed after surgical treatment giving an overall survival rate of $82.4 \%$. When considering KM width, 11 out of 39 implants (28.2\%) were removed in the $<2 \mathrm{~mm} \mathrm{KM}$ group, while only 1 out of $29 \mathrm{im}$ plants (3.4\%) were lost in the $\geq 2 \mathrm{~mm}$ KM group. Treated implant sites with $<2 \mathrm{~mm} \mathrm{KM}$ displayed a shorter follow-up after treatment ( $p=.075)$ when compared to $\geq 2 \mathrm{~mm}$ KM sites.

After adjusting the model for the number of maintenance visits and MBL at T1, it was found that sites with $<2 \mathrm{~mm} \mathrm{KM}$ had sixfold increased risk for failure relative to sites with $\geq 2 \mathrm{~mm} \mathrm{KM} \mathrm{(} p=.13)$. It should be noted that multivariate analysis yielded that the position of the MBL could predict implant survival rate prior to treatment being rendered ( $p=.05$ ) (Table 4). Seven of the 11 implant failures in the $<2 \mathrm{~mm} \mathrm{KM}$ group presented with $\mathrm{MBL}>50 \%$ at T1. The risk of future implant failure increased by $65 \%$ for each additional millimetre of MBL measured at T1.

In terms of PPD reduction, no statistically significant difference was found after adjusting for differences in follow-up time and number of maintenance visits between the two KM width groups regardless of regenerative $(p=.1)$ or resective therapy $(p=.5)$ (Figure 2a). At 
TABLE 1 Overall demographic data prior to the surgical treatment for peri-implantitis (T1)

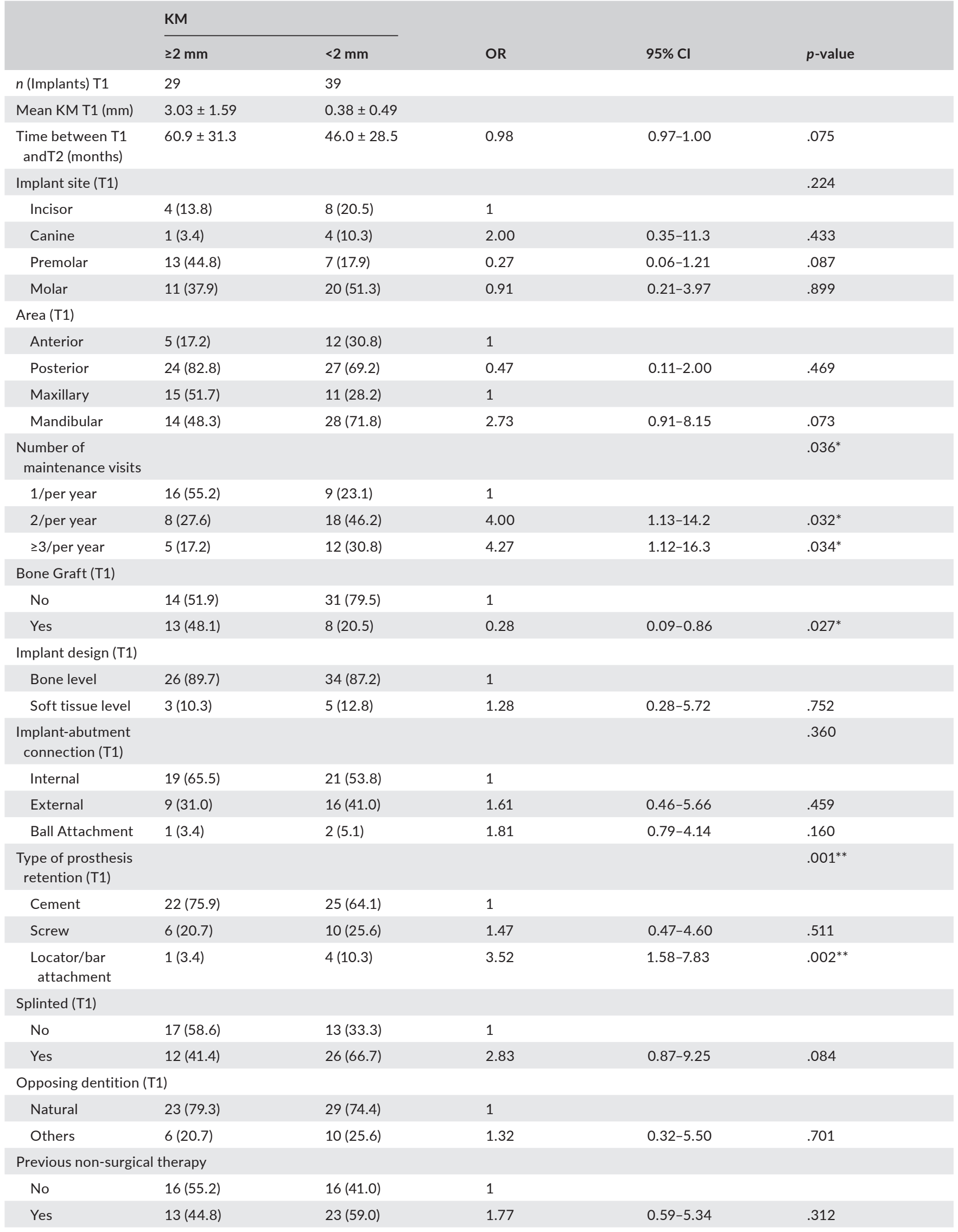


TABLE 1 (Continued)

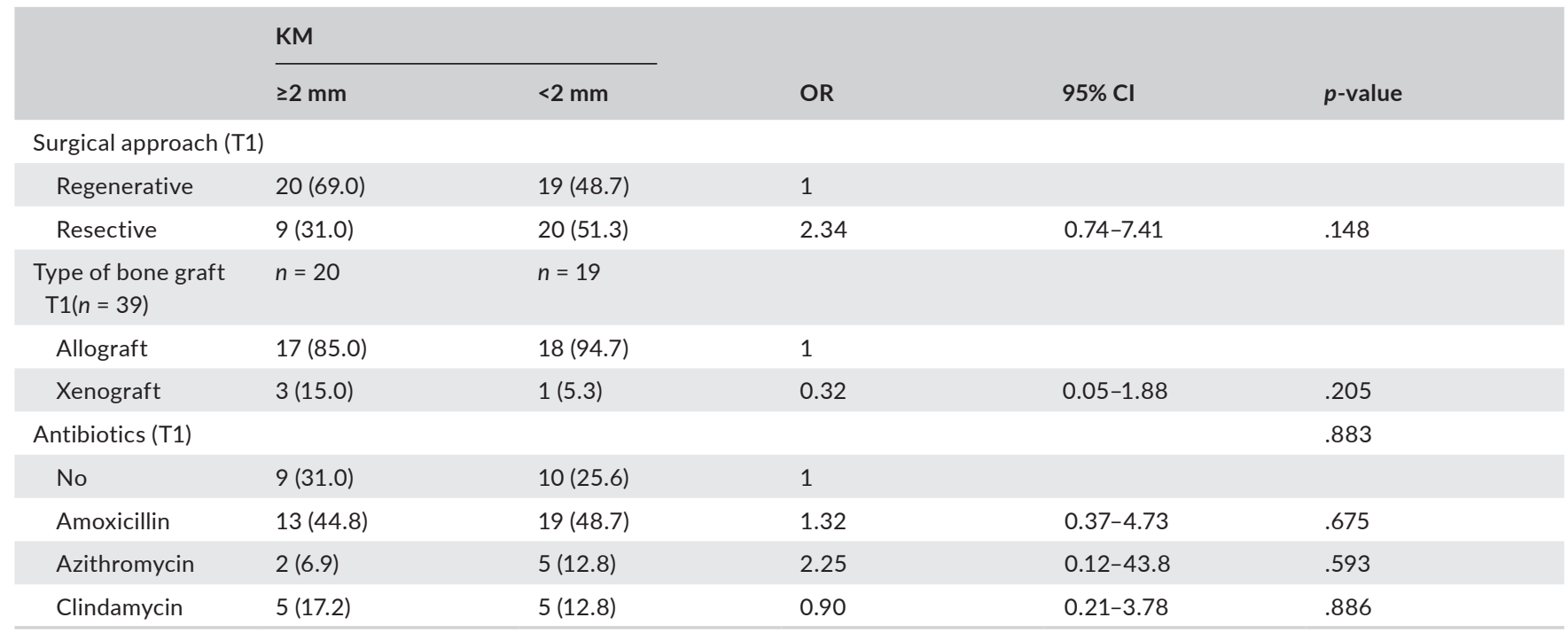

Abbreviation: $\mathrm{KM}$, keratinized mucosa.

${ }^{*} p<.05 ;{ }^{* *} p<.01$.

\begin{tabular}{|llllll|}
\hline & $\geq 2 \mathrm{~mm}$ & $<2 \mathrm{~mm}$ & OR & $95 \% \mathrm{Cl}$ & $p$-value \\
\hline $\begin{array}{llll}\text { n (Implants) } \\
\text { Suppuration }\end{array}$ & 42 & 26 & & & \\
\hline No & $17(40.5)$ & $4(15.4)$ & 1 & & \\
\hline Yes & $25(59.5)$ & $22(84.6)$ & 5.02 & $1.22-20.6$ & $.025^{*}$ \\
\hline BOP & & & & & \\
\hline No & $0(0.0)$ & $0(0.0)$ & & & 1.000 \\
\hline Yes & $42(100)$ & $26(100)$ & - & - & $.014^{*}$ \\
\hline \% MBL & & & & & \\
\hline$<25 \%$ & $30(73.3)$ & $5(19.2)$ & 1 & & $.012^{*}$ \\
\hline $25 \%-50 \%$ & $9(21.5)$ & $13(50.0)$ & 5.43 & $1.45-20.4$ & $.011^{*}$ \\
\hline$>50 \%$ & $3(7.2)$ & $8(30.8)$ & 10.9 & $1.75-67.9$ & $.005^{* *}$ \\
\hline Mean MBL $(\mathrm{mm})$ & $2.66 \pm 1.24$ & $4.38 \pm 2.13$ & 1.62 & $1.15-2.28$ & .451 \\
\hline Mean PPD $(\mathrm{mm})$ & $5.67 \pm 1.59$ & $5.75 \pm 1.34$ & 0.88 & $0.62-1.24$ & \\
\hline
\end{tabular}

TABLE 2 Clinical and radiographical parameters occurring from TO to T1 utilizing the width $\mathrm{KM}$ at TO as the predictor

Abbreviations: BOP, bleeding on probing; MBL, marginal bone level; PPD, peri-implant probing depths.

${ }^{*} p<.05 ;{ }^{* *} p<.01$.

T1, BOP was present at $100 \%$ of peri-implant sites in both groups. At T2, BOP was measured at $90 \%$ of sites in both groups after regenerative therapy, and at $88.9 \%(\mathrm{KM}<2 \mathrm{~mm})$ and $87.5 \%(\mathrm{KM} \geq 2 \mathrm{~mm})$ after resective therapy $(p>.05)$. SUP was reduced from $80 \%$ to $40 \%$ at sites with $<2 \mathrm{~mm} \mathrm{KM}$ and from $60 \%$ to $45 \%$ at sites with $\geq 2 \mathrm{~mm}$ when treated with regenerative therapy $(p>.05)$. SUP decreased from $72.2 \%$ to $5.6 \%$ in the $<2 \mathrm{~mm} \mathrm{KM}$ group and from $57 \%$ to $42.9 \%$ at sites with $\geq 2 \mathrm{~mm} \mathrm{KM}$ after resective therapy $(p<.01)$. MBL changes in both KM groups showed no differences $(p>.05)$ between resective or regenerative treatment approaches (Figure $2 b$ ).

During T2, PI scores were $1.37 \pm 0.88$ at the sites with $<2 \mathrm{~mm}$ $\mathrm{KM}$ and $1.36 \pm 0.81$ at sites with $\geq 2 \mathrm{~mm} \mathrm{KM}(p>.05)$. Gl score was significantly $(p=.013)$ lower at sites with $<2 \mathrm{~mm} \mathrm{KM}(1.56 \pm 0.64)$ when compared to the $\geq 2 \mathrm{~mm} \mathrm{KM}$ group (1.92 \pm 0.57$)$. Maintenance frequency exhibited a significant effect on $\mathrm{Gl}$ score (beta $=-0.33$, $p=.001$ ); for each additional annual maintenance visit, the GI score was reduced by 0.20 points.

\section{3 | Success rate after treatment of peri-implantitis}

Table 5 shows the number and percentage of implants that responded to surgical therapy. Based on the selected criteria, the overall treatment success was accomplished in $10.3 \%$ and $7.7 \%$ of cases among sites with $\geq 2 \mathrm{~mm}$ and $<2 \mathrm{~mm} \mathrm{KM}$, respectively. Success rates were $9.1 \%$ and $23.5 \%$ when regeneration therapy was performed at 
TABLE 3 Clinical and radiographical parameters prior to surgical treatment of peri-implantitis (T1)

\begin{tabular}{|c|c|c|c|c|c|}
\hline & \multicolumn{2}{|l|}{ KM } & \multirow[b]{2}{*}{ OR } & \multirow[b]{2}{*}{$95 \% \mathrm{Cl}$} & \multirow[b]{2}{*}{$p$-value } \\
\hline & $\geq 2 \mathrm{~mm}$ & $<2 \mathrm{~mm}$ & & & \\
\hline n (Implants) & 29 & 39 & & & \\
\hline \multicolumn{6}{|l|}{ Suppuration } \\
\hline No & $13(44.8)$ & $8(20.5)$ & 1 & & \\
\hline Yes & $16(55.2)$ & $31(79.5)$ & 3.15 & $0.99-10.0$ & .052 \\
\hline \multicolumn{6}{|l|}{ BOP } \\
\hline No & $0(0.0)$ & $0(0.0)$ & & & \\
\hline Yes & $29(100)$ & 39 (100) & - & - & 1.000 \\
\hline$\% \mathrm{MBL}$ & & & & & $.004^{* *}$ \\
\hline$<25 \%$ & $22(75.9)$ & $13(33.3)$ & 1 & & \\
\hline $25 \%-50 \%$ & 5 (17.2) & $17(43.6)$ & 6.22 & $1.79-21.7$ & $.004^{* *}$ \\
\hline$>50 \%$ & $2(6.9)$ & 9 (23.1) & 8.25 & $1.45-47.0$ & $.018^{*}$ \\
\hline Mean MBL (mm) & $2.47 \pm 1.25$ & $3.98 \pm 1.95$ & 1.87 & $1.23-2.85$ & $.003^{* *}$ \\
\hline Mean PPD (mm) & $5.79 \pm 1.57$ & $5.63 \pm 1.44$ & 0.93 & $0.69-1.26$ & .628 \\
\hline
\end{tabular}

Abbreviations: BOP, bleeding on probing; MBL, marginal bone level; PPD, peri-implant probing depths.

${ }^{*} p<.05 ;{ }^{* *} p<.01 ;{ }^{* * *} p<.001$.

\begin{tabular}{|c|c|c|c|c|c|}
\hline & \multicolumn{2}{|c|}{ Implant failure } & \multirow[b]{2}{*}{ OR } & \multirow[b]{2}{*}{$95 \% \mathrm{Cl}$} & \multirow[b]{2}{*}{$p$-value } \\
\hline & No & Yes & & & \\
\hline n (implant) & 56 & 12 & & & \\
\hline \multicolumn{6}{|l|}{ KM } \\
\hline$\geq 2 \mathrm{~mm}$ & $28(96.6)$ & $1(3.4)$ & 1 & & \\
\hline$<2 \mathrm{~mm}$ & 28 (71.8) & $11(28.2)$ & 5.55 & $0.59-52.3$ & .13 \\
\hline $\begin{array}{l}\text { Number of } \\
\text { maintenance visits }\end{array}$ & & & 0.96 & $0.45-2.05$ & .91 \\
\hline MBL & & & 1.65 & $0.99-2.72$ & .05 \\
\hline
\end{tabular}

TABLE 4 Clinical and radiographical parameters between $\mathrm{T} 1$ and $\mathrm{T} 2$ adjusted by number of maintenance visits and MBL utilizing $\mathrm{KM}$ at $\mathrm{T} 1$ as predictor sites with $\geq 2 \mathrm{~mm}$ and $<2 \mathrm{~mm} \mathrm{KM}$, respectively. Overall, no significant influence of the KM width on the criteria was found between the groups $(p>.05)$.

\section{DISCUSSION}

\section{1 | Principal findings}

The significance of KM width on frequency of peri-implant diseases is a heavily debated subject in the literature. Current evidence underlines the importance of frequent periodontal and peri-implant maintenance, suggesting that in highly compliant patients, KM plays a null role in the prevention of biological complications (Lim et al., 2019). Conversely, in poorly compliant patients, the presence of $\geq 2 \mathrm{~mm}$ of KM has been demonstrated to be beneficial for long-term outcomes (Monje \& Blasi, 2019; Romanos, Grizas, \& Nentwig, 2015). Generally, the influence of peri-implant KM on peri-implantitis therapeutic outcomes is poorly understood.
Findings from this retrospective analysis suggest that peri-implant sites with minimal KM display more severe forms of peri-implantitis. Nevertheless, our results failed to exhibit an association between the width of the initial band of KM and the therapeutic outcome of peri-implantitis. Our findings revealed that lower MBL around implants prior to surgical treatment contributes towards therapeutical success and implant survival to a greater extent than KM width. However, the presence of $\geq 2 \mathrm{~mm}$ of $\mathrm{KM}$ around implant sites diagnosed with peri-implantitis led to higher survival rates compared to sites lacking KM. Regardless of the presence or absence of KM, severe forms of peri-implantitis are more prone to showing unsatisfactory outcomes after surgical therapy. Following treatment, BOP was yet measured at $90 \%$ of sites in both groups after either therapies. Noticeable variations between the incidence of BOP and clinically manifested peri-implantitis was previously reported (Mombelli, Muller, \& Cionca, 2012). More recently, another group reported that following surgical peri-implantitis therapy, no BOP was demonstrated in only $14 \%$ of implants treated, and almost only $2 \%$ at patient level 
(Koldsland, Wohlfahrt, \& Aass, 2018). Both findings in addition to the results of the current study agree with the conclusions of a recent systematic review; that the extent to which BOP can identify peri-implantitis seems to be limited (Hashim, Cionca, Combescure, \& Mombelli, 2018). Noteworthy is also that only one group ( $K M \geq 2 \mathrm{~mm}$ ) experienced bone gain (Figure $2 \mathrm{~b}$ ). This might be partially explained by the wide-ranging standard deviation we had, were few implants had modest amounts of bone gain, others had significant bone loss. In contrast, a systematic review reported that $10.4 \%$ of the included implants from six clinical trials showed complete bone fill, $85.5 \%$ showed partial defect fill and only $4 \%$ experienced bone loss (Sahrmann, Attin, \& Schmidlin, 2011).

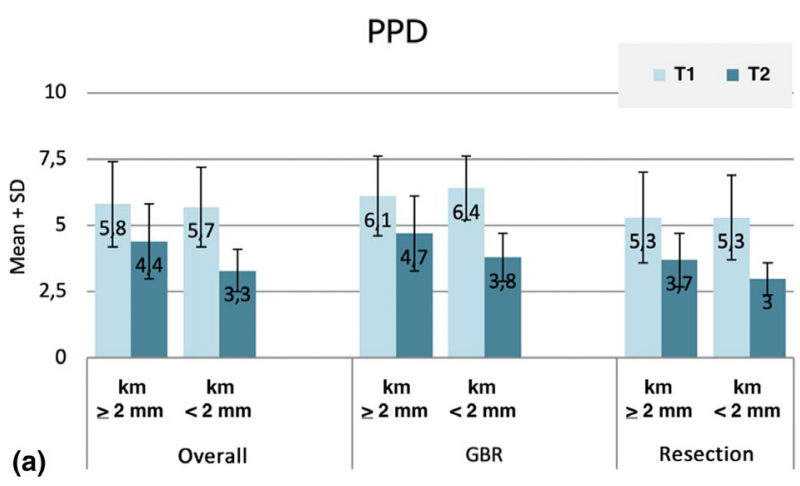

MBL

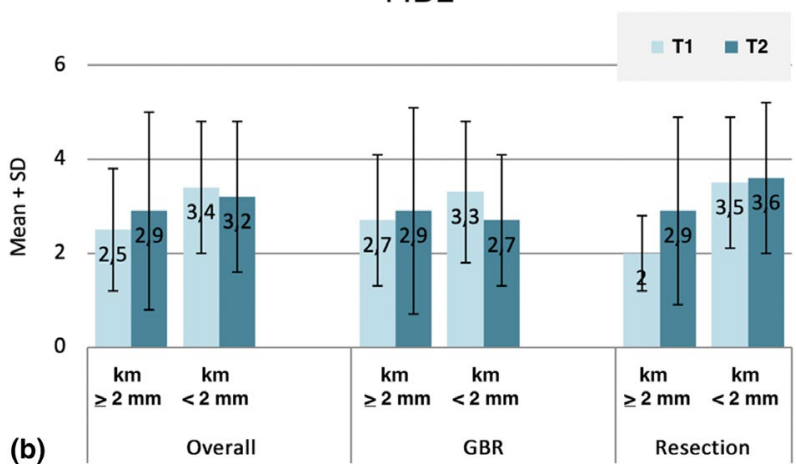

FIGURE 2 Changes in probing pocket depths (PPDs) (a) and implant marginal bone loss (MBL) (b) between T1 and T2 according keratinized mucosa (KM) width

\subsection{Agreements and disagreements with previous studies}

Peri-implantitis is characterized by a non-linear and accelerating pattern of peri-implant marginal bone loss (Derks et al., 2016), where a lack of KM has been suggested to contribute towards the onset of periimplantitis (Gobbato et al., 2013; Lin et al., 2013). In fact, a very recent prospective follow-up study demonstrated that $\mathrm{KM}$ width and time in function had a statistically significant effect on MBL (Perussolo, Souza, Matarazzo, Oliveira, \& Araujo, 2018). This was supportive of previous findings (Zigdon \& Machtei, 2008). Schwarz et al. (2018a) showed that sites with $\geq 2 \mathrm{~mm} K \mathrm{KM}$ displayed less efficient resolution of experimental peri-implant mucositis. Our findings underlined that the lack of KM contributes towards increased peri-implantitis severity.

This study is the first to investigate the impact of KM width on peri-implantitis therapeutic outcomes. Recent clinical trials concurred that non-surgical treatments are often insufficient in preventing further bone loss at peri-implantitis sites, and that only surgical approaches significantly diminish the progression of bone loss (Faggion, Listl, Fruhauf, Chang, \& Tu, 2014; Karlsson et al., 2019). It is also safe to assume that surgical interventions are best reserved for moderate and advanced peri-implantitis cases (Aljateeli, Fu, \& Wang, 2012; Esposito, Grusovin, \& Worthington, 2012). As for the modality of surgery, a systematic review that investigated different surgical modalities for treatment of peri-implantitis was unable to support a specific type of treatment modality (Heitz-Mayfield \& Mombelli, 2014). Our findings further elucidated that advanced bone loss present at the time of peri-implantitis treatment has a major impact on determining therapeutic outcomes. Hence, the therapeutic prognosis of advanced forms of peri-implantitis in the vast majority of cases is unfavourable or hopeless, regardless of the presence or lack of KM. In this sense, 7 of the 11 failures in the $<2 \mathrm{~mm}$ KM group presented at T1 with MBL > 50\%. Our study demonstrated there was no difference in PI, PPD reduction or MBL between both KM groups at T2. However, the effects of KM width on SUP need further clarification, since resective procedures decreased SUP from $72.2 \%$ to $5.6 \%$ in the $<2 \mathrm{~mm} \mathrm{KM}$ group, but only decreased SUP from $57 \%$ to $42.9 \%$ in the $\geq 2 \mathrm{~mm} \mathrm{KM}$ group ( $p<.01$ ). It is speculated that this marked reduction of SUP is merely due to the high implant failure rate seen in the $<2 \mathrm{~mm} \mathrm{KM}$ group, where nine implants with SUP failed, and thus were not included in the analysis. Based on our analysis, each

\begin{tabular}{|c|c|c|c|c|c|}
\hline & \multicolumn{2}{|l|}{ KM } & \multirow[b]{2}{*}{ OR } & \multirow[b]{2}{*}{$95 \% \mathrm{Cl}$} & \multirow[b]{2}{*}{$p$-value } \\
\hline & $\geq 2 \mathrm{~mm}$ & $<2 \mathrm{~mm}$ & & & \\
\hline n (Implants) & 29 & 39 & & & \\
\hline \multicolumn{6}{|l|}{ Criteria 1} \\
\hline Success & $3(10.3)$ & $3(7.7)$ & 1 & & \multirow[t]{2}{*}{.704} \\
\hline Failure & $26(89.7)$ & $36(92.3)$ & 1.39 & $0.26-7.41$ & \\
\hline$n$ (Implants) & 22 & 17 & & & \\
\hline \multicolumn{6}{|c|}{ Criteria 2 (Regeneration) } \\
\hline Success & $2(9.1)$ & $4(23.5)$ & 1 & & \multirow[t]{2}{*}{.299} \\
\hline Failure & $20(90.9)$ & $13(76.5)$ & 0.33 & $0.04-2.65$ & \\
\hline
\end{tabular}

TABLE 5 Treatment success rate at final recall (T2) 
additional millimetre of $\mathrm{MBL}$ increased the risk of implant failure by $65 \%$. While such association has not been reported in previous clinical trials, it seems to be in agreement with the general consensus of the literature (Froum \& Rosen, 2012; Schwarz, Sahm, Schwarz, \& Becker, 2010; Sinjab, Garaicoa-Pazmino, \& Wang, 2018).

All patients recruited for this study were compliant with peri-implant maintenance therapy having a minimum of one maintenance session per year after treatment of peri-implantitis. A recent study investigated the outcomes of surgically treated implants with peri-implantitis that were maintained regularly (Serino, Turri, \& Lang, 2015). Results showed that $39 \%$ of the treated implants had concomitant BOP/SUP upon probing after 6 months. Interestingly, in our study $\mathrm{GI}$ scores were significantly lower at sites with $<2 \mathrm{~mm} \mathrm{KM}$ $(1.56 \pm 0.64)$ than sites with $\geq 2 \mathrm{~mm} \mathrm{KM}(1.92 \pm 0.57)$. It is noteworthy that our patients that fell within the $<2 \mathrm{~mm} \mathrm{KM}$ group exhibited a relatively increased frequency of supportive peri-implant maintenance visits from T1 to T2. This is in agreement with previous findings (Lim et al., 2019).

Treatment success was set according to the most commonly used criteria proposed by Heitz-Mayfield and Mombelli (Heitz-Mayfield \& Mombelli, 2014) and a specific criteria intended for regenerative approaches (Mombelli et al., 1987; Renvert, Roos-Jansaker, et al., 2018; Roos-Jansaker et al., 2014). Our treatment success rates might seem to be significantly lower compared with other studies (Heitz-Mayfield et al., 2018; Renvert, Roos-Jansaker, et al., 2018), mainly due to a high rate of residual BOP at T2. BOP has been suggested to be a clinical sign of peri-implant mucositis and peri-implantitis. As inferred before, the magnitude to which BOP, as a single variant, indicates the presence of peri-implantitis remains unknown (Monje, Caballe-Serrano, et al., 2018a). Marked variations between the incidence of BOP and clinically manifested peri-implantitis exist (Mombelli et al., 2012). In fact, assessments comparing teeth and implants in the same patients have shown that in the absence of disease, BOP was more frequent at implant sites (Cionca, Hashim, Cancela, Giannopoulou, \& Mombelli, 2016). These findings could result from disturbing blood vessels due to an increased depth of probe penetration into healthy peri-implant mucosa. Hence, careful interpretation of BOP values is necessary, since it might lead to a high false-positive rate when identifying the presence of peri-implant disease. Assessment of bleeding tendency using the modified sulcus bleeding index, or mucosal inflammation using the implant mucosal index, is likely more accurate in the detection of true peri-implant breakdown (French, Cochran, \& Ofec, 2016; Mombelli et al., 1987; Monje, Insua, et al., 2018b).

\section{3 | Limitations and recommendations for future studies}

Our study is not free of limitations inherent to the retrospective design of the investigation. Although our study included only compliant patients, some could be considered erratic compliers $(<2$ visits/year). Erratic compliers have been reported to perform as poorly as non-compliant patients (Monje, Wang, \& Nart, 2017). Furthermore, the length, diameter, brand and surface treatment of implants were not included in the multivariate analysis, since the number of implant variations used was too substantial to yield statistical significance for the patient sample studied. Due to the multi-level design of the statistical analysis, a power of $72 \%$ was reached.

It should be noticed that the implant literature has been scarce in terms of considering KM association with the outcome of surgical procedures of peri-implantitis. Efforts should therefore be undertaken to include such outcome measures in future clinical studies.

\section{5 | CONCLUSION}

Peri-implant bone loss as a result of peri-implantitis is further aggravated in scenarios lacking KM. Nevertheless, surgical outcome in treating peri-implantitis was influenced by the severity of bone loss present at the time of treatment and not by the presence of keratinized mucosa at the time of treatment. Hence, the assessment of peri-implant bone loss prior to surgical therapy is a more accurate predictor of therapeutic outcomes when treating peri-implantitis.

\section{ACKNOWLEDGEMENTS}

The authors would like to thank Dr. Matthew Galli (Department of Periodontics and Oral Medicine, University of Michigan School of Dentistry) for his contribution on the preparation of the manuscript.

\section{CONFLICT OF INTEREST}

The authors do not have any financial interests, either directly or indirectly, in the products or information listed in the paper.

\section{ORCID}

Andrea Ravidà (iD https://orcid.org/0000-0002-3029-8130

Rafael Siqueira (iD https://orcid.org/0000-0003-4081-0959

Carlos Garaicoa-Pazmiño iD https://orcid.

org/0000-0001-8486-6810

Alberto Monje iD https://orcid.org/0000-0001-8292-1927

Hom-Lay Wang iD https://orcid.org/0000-0003-4238-1799

\section{REFERENCES}

Aljateeli, M., Fu, J. H., \& Wang, H. L. (2012). Managing peri-implant bone loss: Current understanding. Clinical Implant Dentistry and Related Research, 14(Suppl 1), e109-e118. https://doi. org/10.1111/j.1708-8208.2011.00387.x

Bengazi, F., Wennstrom, J. L., \& Lekholm, U. (1996). Recession of the soft tissue margin at oral implants. A 2-year longitudinal prospective study. Clinical Oral Implants Research, 7, 303-310. https://doi. org/10.1034/j.1600-0501.1996.070401.x

Berglundh, T., Armitage, G., Araujo, M. G., Avila-Ortiz, G., Blanco, J., Camargo, P. M., ... Zitzmann, N. (2018). Peri-implant diseases and conditions: Consensus report of workgroup 4 of the 2017 World Workshop on the Classification of Periodontal and Peri-Implant Diseases and Conditions. Journal of Clinical Periodontology, 45(Suppl 20), S286-S291. https://doi.org/10.1111/jcpe.12957 
Berglundh, T., Wennstrom, J. L., \& Lindhe, J. (2018). Long-term outcome of surgical treatment of peri-implantitis. A 2-11-year retrospective study. Clinical Oral Implants Research, 29, 404-410. https://doi. org/10.1111/clr.13138

Bouri, A. Jr, Bissada, N., Al-Zahrani, M. S., Faddoul, F., \& Nouneh, I. (2008). Width of keratinized gingiva and the health status of the supporting tissues around dental implants. International Journal of Oral and Maxillofacial Implants, 23, 323-326.

Cha, J. K., Lee, J. S., \& Kim, C. S. (2019). Surgical therapy of peri-implantitis with local minocycline: A 6-month randomized controlled clinical trial. Journal of Dental Research, 98, 288-295. https://doi. org/10.1177/0022034518818479

Charalampakis, G., Rabe, P., Leonhardt, A., \& Dahlen, G. (2011). A follow-up study of peri-implantitis cases after treatment. Journal of Clinical Periodontology, 38, 864-871. https://doi. org/10.1111/j.1600-051X.2011.01759.x

Chung, D. M., Oh, T. J., Shotwell, J. L., Misch, C. E., \& Wang, H. L. (2006). Significance of keratinized mucosa in maintenance of dental implants with different surfaces. Journal of Periodontology, 77, 1410-1420. https://doi.org/10.1902/jop.2006.050393

Cionca, N., Hashim, D., Cancela, J., Giannopoulou, C., \& Mombelli, A. (2016). Pro-inflammatory cytokines at zirconia implants and teeth. A cross-sectional assessment. Clinical Oral Investigations, 20, 22852291. https://doi.org/10.1007/s00784-016-1729-z

Crespi, R., Cappare, P., \& Gherlone, E. (2010). A 4-year evaluation of the peri-implant parameters of immediately loaded implants placed in fresh extraction sockets. Journal of Periodontology, 81, 1629-1634. https://doi.org/10.1902/jop.2010.100115

de Tapia, B., Valles, C., Ribeiro-Amaral, T., Mor, C., Herrera, D., Sanz, M., \& Nart, J. (2019). The adjunctive effect of a titanium brush in implant surface decontamination at peri-implantitis surgical regenerative interventions: A randomized controlled clinical trial. Journal of Clinical Periodontology, 46, 586-596. https://doi.org/10.1111/ jcpe.13095

Derks, J., Schaller, D., Hakansson, J., Wennstrom, J. L., Tomasi, C., \& Berglundh, T. (2016). Peri-implantitis - Onset and pattern of progression. Journal of Clinical Periodontology, 43, 383-388. https://doi. org/10.1111/jcpe.12535

Derks, J., \& Tomasi, C. (2015). Peri-implant health and disease. A systematic review of current epidemiology. Journal of Clinical Periodontology, 42(Suppl 16), S158-S171. https://doi.org/10.1111/jcpe.12334

Esposito, M., Grusovin, M. G., \& Worthington, H. V. (2012). Interventions for replacing missing teeth: Treatment of peri-implantitis. Cochrane Database Systematic Review, 1, CD004970. https://doi. org/10.1002/14651858.CD004970.pub5

Faggion, C. M. Jr, Listl, S., Fruhauf, N., Chang, H. J., \& Tu, Y. K. (2014). A systematic review and Bayesian network meta-analysis of randomized clinical trials on non-surgical treatments for peri-implantitis. Journal of Clinical Periodontology, 41, 1015-1025. https://doi. org/10.1111/jcpe.12292

French, D., Cochran, D. L., \& Ofec, R. (2016). Retrospective Cohort Study of 4,591 Straumann implants placed in 2,060 patients in private practice with up to 10-year follow-up: The relationship between crestal bone level and soft tissue condition. International Journal of Oral and Maxillofacial Implants, 31, e168-e178. https://doi.org/10.11607/ jomi.4932

Frisch, E., Ziebolz, D., Vach, K., \& Ratka-Kruger, P. (2015). The effect of keratinized mucosa width on peri-implant outcome under supportive postimplant therapy. Clinical Implant Dentistry and Related Research, 17(Suppl 1), e236-244. https://doi.org/10.1111/cid.12187

Froum, S. J., \& Rosen, P. S. (2012). A proposed classification for peri-implantitis. International Journal of Periodontics \& Restorative Dentistry, 32, 533-540.

Gobbato, L., Avila-Ortiz, G., Sohrabi, K., Wang, C. W., \& Karimbux, N. (2013). The effect of keratinized mucosa width on peri-implant health:
A systematic review. International Journal of Oral and Maxillofacial Implants, 28, 1536-1545. https://doi.org/10.11607/jomi.3244

Hammerle, C. H. F., \& Tarnow, D. (2018). The etiology of hard- and soft-tissue deficiencies at dental implants: A narrative review. Journal of Clinical Periodontology, 45(Suppl 20), S267-S277. https:// doi.org/10.1111/jcpe.12955

Hashim, D., Cionca, N., Combescure, C., \& Mombelli, A. (2018). The diagnosis of peri-implantitis: A systematic review on the predictive value of bleeding on probing. Clinical Oral Implants Research, 29(Suppl 16), 276-293. https://doi.org/10.1111/clr.13127

Heitz-Mayfield, L. J., \& Mombelli, A. (2014). The therapy of peri-implantitis: A systematic review. International Journal of Oral and Maxillofacial Implants, 29(Suppl), 325-345. https://doi.org/10.11607/jomi.2014s uppl.g5.3

Heitz-Mayfield, L. J. A., Salvi, G. E., Mombelli, A., Loup, P. J., Heitz, F., Kruger, E., \& Lang, N. P. (2018). Supportive peri-implant therapy following anti-infective surgical peri-implantitis treatment: 5 -year survival and success. Clinical Oral Implants Research, 29, 1-6. https://doi. org/10.1111/clr.12910

Howe, M. S., Keys, W., \& Richards, D. (2019). Long-term (10-year) dental implant survival: A systematic review and sensitivity meta-analysis. Journal of Dentistry, 84, 9-21. https://doi.org/10.1016/j. jdent.2019.03.008

Isler, S. C., Soysal, F., Ceyhanli, T., Bakirarar, B., \& Unsal, B. (2018). Regenerative surgical treatment of peri-implantitis using either a collagen membrane or concentrated growth factor: A 12-month randomized clinical trial. Clinical Implant Dentistry and Related Research, 20, 703-712. https://doi.org/10.1111/cid.12661

Karlsson, K., Derks, J., Hakansson, J., Wennstrom, J. L., Petzold, M., \& Berglundh, T. (2019). Interventions for peri-implantitis and their effects on further bone loss: A retrospective analysis of a registry-based cohort. Journal of Clinical Periodontology, 46(8), 872-879. https://doi.org/10.1111/jcpe.13129

Kim, B. S., Kim, Y. K., Yun, P. Y., Yi, Y. J., Lee, H. J., Kim, S. G., \& Son, J. S. (2009). Evaluation of peri-implant tissue response according to the presence of keratinized mucosa. Oral Surgery, Oral Medicine, Oral Pathology, Oral Radiology and Endodontics, 107, e24-28. https://doi. org/10.1016/j.tripleo.2008.12.010

Koldsland, O. C., Wohlfahrt, J. C., \& Aass, A. M. (2018). Surgical treatment of peri-implantitis: Prognostic indicators of short-term results. Journal of Clinical Periodontology, 45, 100-113. https://doi. org/10.1111/jcpe.12816

Lim, H. C., Wiedemeier, D. B., Hammerle, C. H. F., \& Thoma, D. S. (2019). The amount of keratinized mucosa may not influence peri-implant health in compliant patients: A retrospective 5-year analysis. Journal of Clinical Periodontology, 46, 354-362. https://doi.org/10.1111/jcpe.13078

Lin, G. H., Chan, H. L., \& Wang, H. L. (2013). The significance of keratinized mucosa on implant health: A systematic review. Journal of Periodontology, 84, 1755-1767. https://doi.org/10.1902/ jop.2013.120688

Lindhe, J., Meyle, J. \& Group, D. o. E. W. o. P (2008). Peri-implant diseases: Consensus Report of the Sixth European Workshop on Periodontology. Journal of Clinical Periodontology, 35, 282-285. https ://doi.org/10.1111/j.1600-051X.2008.01283.x

Listgarten, M. A., Lang, N. P., Schroeder, H. E., \& Schroeder, A. (1991). Periodontal tissues and their counterparts around endosseous implants. Clinical Oral Implants Research, 2(3), 1-19. https://doi. org/10.1034/j.1600-0501.1991.020309.x

Mombelli, A., Muller, N., \& Cionca, N. (2012). The epidemiology of peri-implantitis. Clinical Oral Implants Research, 23(Suppl 6), 67-76. https://doi.org/10.1111/j.1600-0501.2012.02541.x

Mombelli, A., van Oosten, M. A., Schurch, E. Jr, \& Land, N. P. (1987). The microbiota associated with successful or failing osseointegrated titanium implants. Oral Microbiology and Immunology, 2, 145-151. https ://doi.org/10.1111/j.1399-302X.1987.tb00298.x 
Monje, A., \& Blasi, G. (2019). Significance of keratinized mucosa/gingiva on peri-implant and adjacent periodontal conditions in erratic maintenance compliers. Journal of Periodontology, 90, 445-453. https:// doi.org/10.1002/JPER.18-0471

Monje, A., Caballe-Serrano, J., Nart, J., Penarrocha, D., Wang, H. L., \& Rakic, M. (2018a). Diagnostic accuracy of clinical parameters to monitor peri-implant conditions: A matched case-control study. Journal of Periodontology, 89, 407-417. https://doi.org/10.1002/JPER.17-0454

Monje, A., Insua, A., Rakic, M., Nart, J., Moyano-Cuevas, J. L., \& Wang, H. L. (2018b). Estimation of the diagnostic accuracy of clinical parameters for monitoring peri-implantitis progression: An experimental canine study. Journal of Periodontology, 89, 1442-1451. https://doi. org/10.1002/JPER.18-0081

Monje, A., Wang, H. L., \& Nart, J. (2017). Association of preventive maintenance therapy compliance and peri-implant diseases: A cross-sectional study. Journal of Periodontology, 88, 1030-1041. https://doi. org/10.1902/jop.2017.170135

Perussolo, J., Souza, A. B., Matarazzo, F., Oliveira, R. P., \& Araujo, M. G. (2018). Influence of the keratinized mucosa on the stability of peri-implant tissues and brushing discomfort: A 4-year follow-up study. Clinical Oral Implants Research, 29, 1177-1185. https://doi. org/10.1111/clr.13381

Pjetursson, B. E., Thoma, D., Jung, R., Zwahlen, M., \& Zembic, A. (2012). A systematic review of the survival and complication rates of implant-supported fixed dental prostheses (FDPs) after a mean observation period of at least 5 years. Clinical Oral Implants Research, 23(Suppl 6), 22-38. https://doi.org/10.1111/j.1600-0501.2012.02546.x

Renvert, S., Persson, G. R., Pirih, F. Q., \& Camargo, P. M. (2018). Periimplant health, peri-implant mucositis, and peri-implantitis: Case definitions and diagnostic considerations. Journal of Clinical Periodontology, 45(Suppl 20), S278-S285. https://doi.org/10.1111/ jcpe.12956

Renvert, S., Roos-Jansaker, A. M., \& Persson, G. R. (2018). Surgical treatment of peri-implantitis lesions with or without the use of a bone substitute-a randomized clinical trial. Journal of Clinical Periodontology, 45, 1266-1274. https://doi.org/10.1111/jcpe.12986

Romanos, G., Grizas, E., \& Nentwig, G. H. (2015). Association of keratinized mucosa and periimplant soft tissue stability around implants with platform switching. Implant Dentistry, 24, 422-426. https://doi. org/10.1097/ID.0000000000000274

Roos-Jansaker, A. M., Lindahl, C., Renvert, H., \& Renvert, S. (2006). Nineto fourteen-year follow-up of implant treatment. Part II: Presence of peri-implant lesions. Journal of Clinical Periodontology, 33, 290-295. https://doi.org/10.1111/j.1600-051X.2006.00906.X

Roos-Jansaker, A. M., Persson, G. R., Lindahl, C., \& Renvert, S. (2014). Surgical treatment of peri-implantitis using a bone substitute with or without a resorbable membrane: A 5-year follow-up. Journal of Clinical Periodontology, 41, 1108-1114. https://doi.org/10.1111/ jcpe.12308

Sahrmann, P., Attin, T., \& Schmidlin, P. R. (2011). Regenerative treatment of peri-implantitis using bone substitutes and membrane: A systematic review. Clinical Implant Dentistry and Related Research, 13, 46-57. https://doi.org/10.1111/j.1708-8208.2009.00183.x

Schwarz, F., Becker, J., Civale, S., Sahin, D., Iglhaut, T., \& Iglhaut, G. (2018a). Influence of the width of keratinized tissue on the development and resolution of experimental peri-implant mucositis lesions in humans. Clinical Oral Implants Research, 29, 576-582. https://doi. org/10.1111/clr.13155
Schwarz, F., Becker, J., Civale, S., Sahin, D., Iglhaut, T., \& Iglhaut, G. (2018b). Influence of the width of keratinized tissue on the development and resolution of experimental peri-implant mucositis lesions in humans. Clinical Oral Implants Research, 29(6), 576-582. https://doi. org/10.1111/clr.13155

Schwarz, F., Derks, J., Monje, A., \& Wang, H. L. (2018). Peri-implantitis. Journal of Clinical Periodontology, 45(Suppl 20), S246-S266. https:// doi.org/10.1111/jcpe.12954

Schwarz, F., Sahm, N., Schwarz, K., \& Becker, J. (2010). Impact of defect configuration on the clinical outcome following surgical regenerative therapy of peri-implantitis. Journal of Clinical Periodontology, 37, 449455. https://doi.org/10.1111/j.1600-051X.2010.01540.x

Serino, G., Turri, A., \& Lang, N. P. (2015). Maintenance therapy in patients following the surgical treatment of peri-implantitis: A 5-year follow-up study. Clinical Oral Implants Research, 26, 950-956. https:// doi.org/10.1111/clr.12418

Silness, J., \& Loe, H. (1964). Periodontal disease in Pregnancy II. Correlation between oral hygiene and periodontal condtion. Acta Odontologica Scandinavica, 22, 121-135.

Sinjab, K., Garaicoa-Pazmino, C., \& Wang, H. L. (2018). Decision making for management of periimplant diseases. Implant Dentistry, 27, 276281. https://doi.org/10.1097/ID.0000000000000775

Tonetti, M. S., Greenwell, H., \& Kornman, K. S. (2018). Staging and grading of periodontitis: Framework and proposal of a new classification and case definition. Journal of Periodontology, 89(Suppl 1), S159-S172. https://doi.org/10.1002/JPER.18-0006

Ueno, D., Nagano, T., Watanabe, T., Shirakawa, S., Yashima, A., \& Gomi, K. (2016). Effect of the keratinized mucosa width on the health status of periimplant and contralateral periodontal tissues: A cross-sectional study. Implant Dentistry, 25, 796-801. https://doi.org/10.1097/ ID.0000000000000483

Wennstrom, J. L., Bengazi, F., \& Lekholm, U. (1994). The influence of the masticatory mucosa on the peri-implant soft tissue condition. Clinical Oral Implants Research, 5, 1-8. https://doi. org/10.1034/j.1600-0501.1994.050101.x

Wennstrom, J. L., \& Derks, J. (2012). Is there a need for keratinized mucosa around implants to maintain health and tissue stability? Clinical Oral Implants Research, 23(Suppl 6), 136-146. https://doi. org/10.1111/j.1600-0501.2012.02540.x

Zigdon, H., \& Machtei, E. E. (2008). The dimensions of keratinized mucosa around implants affect clinical and immunological parameters. Clinical Oral Implants Research, 19, 387-392. https://doi. org/10.1111/j.1600-0501.2007.01492.x

\section{SUPPORTING INFORMATION}

Additional supporting information may be found online in the Supporting Information section.

How to cite this article: Ravidà A, Saleh I, Siqueira R, et al. Influence of keratinized mucosa on the surgical therapeutical outcomes of peri-implantitis. J Clin Periodontol. 2020;47:529539. https://doi.org/10.1111/jcpe.13250 